\title{
Anthropometrical Reference Data for Uzbek Women: Results of the Population Research in the Republic of Uzbekistan
}

\author{
Said I. Ismailov, PhD, ScD*; Gulnara N. Rakhimova, PhD, ScD; Anna V. Alieva \\ Center for the Scientific and Clinical Study of Endocrinology \\ Tashkent, The Republic of Uzbekistan
}

\begin{abstract}
The aim of this study was to develop anthropometrical reference data for women of Uzbek nationality. In total, 1413 women of Uzbek nationality aged $\geq 35$ years were studied. BMI was calculated for 411 women. The reference values of BMI for Uzbek women vary from 19.4 to $24.8 \mathrm{~kg} / \mathrm{m}^{2}$; BMI $22.7 \mathrm{~kg} / \mathrm{m}^{2}$ corresponds to the 50 th percentile. These results correspond to the WHO criteria for European populations. The reference values of WC vary from 65.0 to $90.0 \mathrm{~cm}$. The conventional cut-off for normal WC $(80 \mathrm{~cm})$ corresponded to the 75th percentile of the analysis among women of Uzbek nationality without any carbohydrate metabolism disorders and with normal BMI. WC equal to $76 \mathrm{~cm}$ corresponds to the 50th percentile. Thus, the cut-off of WC for Uzbek women is $90.0 \mathrm{~cm}$, which is a mismatch to the European criteria. Average value of WHR was $0.80 \pm 0.07$. Reference values of WHR vary of 0.69 to 0.93 . WHR 0.8 corresponds to the 80 th percentile. The obtained reference ranges are recommended to reveal the prevalence of MS and its components at the stage of revealing of risk groups in Uzbek women. (International Journal of Biomedicine. 2017;7(2):120-125.)
\end{abstract}

Key Words: body mass index • waist circumference • waist-to-hip ratio • hips circumference

\section{Abbreviations}

BMI, body mass index; BP, blood pressure; CVD, cardiovascular diseases; DBP, diastolic BP; FFA, free fatty acids; FPG, fasting plasma glucose; HC, hips circumference; IGT, impaired glucose tolerance; IFG, impaired fasting glucose; OGTT, oral glucose tolerance test; SBP, systolic BP; T2D, type 2 diabetes; WC, waist circumference; WHR, waist-to-hip ratio.

\section{Introduction}

Many studies are devoted to metabolic syndrome (MS) as all its factors lead to development of CVD and T2D. Abdominal obesity and insulin resistance are supposed to be the background of MS. ${ }^{(1-4)}$

As the prevalence of MS is high $-20 \%$ to $25 \%{ }^{(5)}-$ it is clear that the optimal criterion for its diagnosis will be the one that does not demand extra expenses and is not laborconsuming. Therefore, the basic criterion for diagnosis of MS is WC. ${ }^{(1,6-8)}$ According to updated IDF consensus, ${ }^{(8)}$ to be diagnosed with MS, one needs to have central obesity defined as $\mathrm{WC} \geq 94 \mathrm{~cm}$ for Caucasian men and $\geq 80 \mathrm{~cm}$ for Caucasian

*Corresponding author: Prof. Said I. Ismailov. Center for the Scientific and Clinical Study of Endocrinology. Tashkent, Uzbekistan. E-mail: ismailov.said@list.ru women, plus any two of the below mentioned factors for diagnosis of MS:

- triglyceride level $\geq 1.7 \mathrm{mmol} / 1$ or specific treatment;

- HDL level $<1.03 \mathrm{mmol} / 1$ for men and $<1.29 \mathrm{mmol} / 1$ for women or specific treatment;

- $\mathrm{SBP} \geq 130 \mathrm{mmHg}$ and $\mathrm{DBP} \geq 85 \mathrm{mmHg}$ or antihypertensive treatment;

- $\quad F P G \geq 5.6 \mathrm{mmol} / 1$ or earlier diagnosed diabetes.

Thus, the reservation is made that $\mathrm{WC}$ criteria should be specific to each ethnic group. (Tables 1,2)

Active revealing of T2D has a great value, as it has been proved that at the stage of prediabetes (IFG, IGT), patients already may have complications specific to diabetes..$^{(1-3,9)}$ For early diagnosis of $\mathrm{T} 2 \mathrm{D}, \mathrm{WHO}$ recommends a screening at least every 5 years in risk groups, which, in turn, are defined through use of a questionnaire, in particular FindRisk. Besides WC, in the given questionnaire, BMI, age, heredity, hypertension, and 
lifestyle are also considered. Thus, anthropometry indicators are a simple and effective way to obtain an early and mass estimation of risk of developing CVD and T2D.

WC is measured using a centimetric tape on an exhalation, without any expanding or contracting of the belly. ${ }^{(10)}$

Table 1.

Reference data for WC according to IDF recommendations ${ }^{(8)}$

\begin{tabular}{|c|c|c|}
\hline \multicolumn{2}{|c|}{ Country/Ethnic group } & WC \\
\hline \multirow{2}{*}{ Europids } & Male & $\geq 94 \mathrm{~cm}$ \\
\hline & Female & $\geq 80 \mathrm{~cm}$ \\
\hline \multirow{2}{*}{ South Asians } & Male & $\geq 90 \mathrm{~cm}$ \\
\hline & Female & $\geq 80 \mathrm{~cm}$ \\
\hline \multirow{2}{*}{ Chinese } & Male & $\geq 90 \mathrm{~cm}$ \\
\hline & Female & $\geq 80 \mathrm{~cm}$ \\
\hline \multirow{2}{*}{ Japanese } & Male & $\geq 90 \mathrm{~cm}$ \\
\hline & Female & $\geq 80 \mathrm{~cm}$ \\
\hline $\begin{array}{l}\text { Ethnic South and Central } \\
\text { Americans }\end{array}$ & \multicolumn{2}{|c|}{$\begin{array}{l}\text { Use South Asian recommendations until } \\
\text { more specific data are available }\end{array}$} \\
\hline Sub-Saharan Africans & \multicolumn{2}{|c|}{$\begin{array}{l}\text { Use European data until more specific } \\
\text { data are available }\end{array}$} \\
\hline $\begin{array}{l}\text { Eastern Mediterranean } \\
\text { and Middle East (Arab) } \\
\text { populations }\end{array}$ & \multicolumn{2}{|c|}{$\begin{array}{l}\text { Use European data until more specific } \\
\text { data are available }\end{array}$} \\
\hline
\end{tabular}

Table 2.

Additional metabolic criteria for research $(I D F)^{(8)}$

\begin{tabular}{|l|l|}
\hline \multicolumn{1}{|c|}{$\begin{array}{c}\text { Abnormal body fat } \\
\text { distribution }\end{array}$} & $\begin{array}{l}\text { DEXA, CT/MRI, leptin, adiponectin, } \\
\text { liver fat content }\end{array}$ \\
\hline Atherogenic dyslipidemia & ApoB, small LDL particles \\
\hline Dysglycemia & OGTT \\
\hline Insulin resistance & $\begin{array}{l}\text { Fasting insulin/proinsulin levels, } \\
\text { HOMA-IR and other IR indices, clamp } \\
\text { method, FFA }\end{array}$ \\
\hline Vascular dysregulation & $\begin{array}{l}\text { Endothelial dysfunction, } \\
\text { microalbuminuria }\end{array}$ \\
\hline Proinflammatory state & $\begin{array}{l}\text { C-reactive protein, inflammatory } \\
\text { cytokines, decreased adiponectin level }\end{array}$ \\
\hline Prothrombotic state & Fibrinolytic factors, clotting factors \\
\hline Hormonal factors & Pituitary-adrenal axis \\
\hline
\end{tabular}

WHR $[\mathrm{WC}(\mathrm{cm}) / \mathrm{HC}(\mathrm{cm})]$ is the indicator characterizing type of fat distribution. For Caucasian women, normal WHR is $<0.85$, for men $-<0.9$.

There are three types of fat distribution, depending on WHR value (Table 3 ). The android type of fat distribution (socalled "apple-type") is characterized by fat deposition in the area of the waist and abdomen and bears the greatest risk of developing CVD (atherosclerosis, ischemic heart disease, and stroke), T2D, and dyslipidemia.

BMI is calculated using Quetelet's formula: BMI = body weight $(\mathrm{kg}) /$ height $(\mathrm{cm})^{2}$

WHO developed criteria ${ }^{(4,11)}$ and detailed techniques for measuring and estimating such indicators as BMI and waist and hips circumference, but at the same time underlined the necessity of working out national anthropometrical references for each population. Therefore, for example, the cut-off of normal BMI for the European population is $25 \mathrm{~kg} / \mathrm{m}^{2}$, for the Asian populations $-23 \mathrm{~kg} / \mathrm{m}^{2}$ (and a value above $25 \mathrm{~kg} / \mathrm{m}^{2}$ is assessed as obesity). The validity of such recommendations has been shown, in particular by $\mathrm{C}$. Wen and co-authors ${ }^{(5)}$ in a prospective cohort study, that applying European threshold BMI values $\left(25 \mathrm{~kg} / \mathrm{m}^{2}\right)$ instead of Asian ones $\left(23 \mathrm{~kg} / \mathrm{m}^{2}\right)$ leads to underestimating risk of lethal outcomes in $8.6 \%$ of cases and of cardiovascular death in $21.1 \%$.

Table 3.

Types of fat distribution depending on WHR value.

\begin{tabular}{|l|c|}
\hline \multicolumn{1}{|c|}{ WHR } & Type of fat distribution \\
\hline Men: $0.8-0.9$ & Intermediate \\
\hline Women: $0.8-0.85$ & Intermediate \\
\hline Women: $<0.8$ & Hynoid \\
\hline Men: $>0.9$ & Android \\
\hline Women: $>0.85$ & Android \\
\hline
\end{tabular}

On the diagram (Fig. 1), the authors clearly show ${ }^{(6)}$ how widely the prevalence of excess weight and weight deficiency varies depending on the country; therefore, it is not a fact that different populations with identical distribution of BMI will have identical relative risk of morbidity and mortality associated with different degrees of excess weight or its deficit.

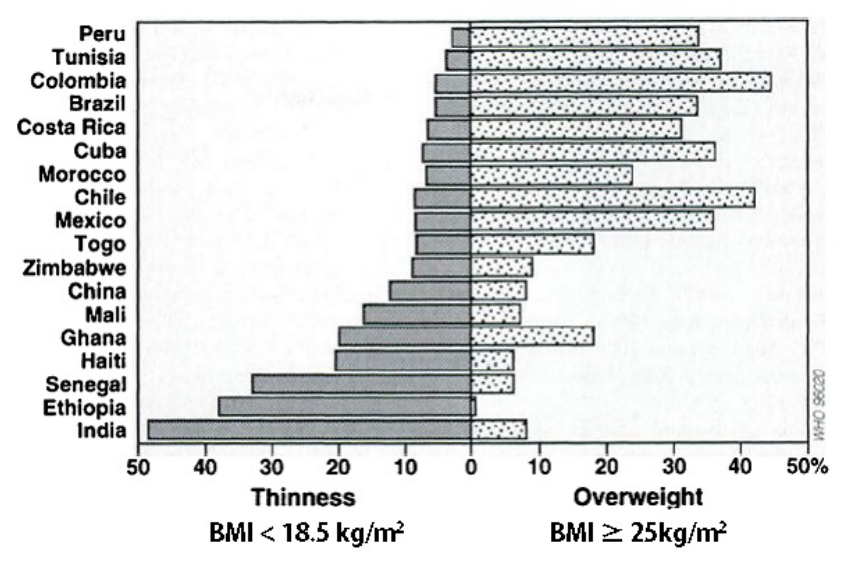

Fig. 1. BMI distribution of various adult populations worldwide

There are a large number of detailed, cited studies in the literature aimed at working out references of anthropometrical indicators for children; ${ }^{(12,13)}$ however, similar studies of adults are lacking for a range of populations. A study was performed on the Uzbek population that worked out percentile tables of WC and BMI for children and teenagers, ${ }^{(14)}$ but there were no similar studies of the adult population.

In 1996, the WHO Expert Committee decided that there is no necessity for reference data on BMI for adults, and interpretation should be performed based on pragmatic 
threshold values. ${ }^{(6)}$ However, subsequent studies have proved the need to develop separate criteria for results of anthropometrical measurements for different populations. Thus, Haldar et al. ${ }^{(15)}$ studied the difference in the amount and distribution of fat between East Asians, South Asians, and Europeans. The authors showed that Asians, having higher BMI than Europeans, are more predisposed to obesity. Additionally, given the same amount of fat tissue, cardiometabolic risk is higher in Asians than in Europeans.

Other authors ${ }^{(16)}$ assessed the possibility of applying European references for BMI and WC to estimate metabolic disorders associated with obesity in Canadians of East Asian and South Asian origin. The authors showed much lower reference values of BMI $\left(23.2 \mathrm{~kg} / \mathrm{m}^{2}\right)$ and WC $(79.6 \mathrm{~cm})$ for the East Asian Canadians than for the South Asian $\left(26.1 \mathrm{~kg} / \mathrm{m}^{2}\right.$ and $90.3 \mathrm{~cm})$ and European Canadians $\left(26.5 \mathrm{~kg} / \mathrm{m}^{2}\right.$ and $\left.89.3 \mathrm{~cm}\right)$

Another research study performed in a multiethnic population of Canada ${ }^{(17)}$ showed that the threshold value for the definition of obesity is approximately $6 \mathrm{~kg} / \mathrm{m}^{2}$ lower for non-European ethnic groups than for European groups(South Asians, Chinese and Canadian natives were studied). Earlier, these authors ${ }^{(18)}$ showed that at the same BMI value in the abovementioned ethnic groups, HbAlc level was higher than in representatives of European races.

Similar results are shown for the Indian population, for which authors recommend lower threshold values for normal BMI. Deurenberg-Yap et al. ${ }^{(19)}$ recommends $27 \mathrm{~kg} / \mathrm{m}^{2}$ as the threshold value of BMI for a diagnosis of obesity in Chinese and Malaysians and $26 \mathrm{~kg} / \mathrm{m}^{2}$ for Hindus.

As for WC, the Canadian authors ${ }^{(16)}$ showed that cut-off values of WC for increased risk of metabolic disorders were lower for the East Asian men (83.3 to $85.2 \mathrm{~cm})$ and women (74.1 to $76.7 \mathrm{~cm})$ than for the South Asian men $(98.8 \mathrm{~cm})$ and women $(90.1$ to $93.5 \mathrm{~cm})$, and also for men $(91.6-95.2 \mathrm{~cm})$ and women $(82.8-88.3 \mathrm{~cm})$ of European origin. In the same study, the authors provide cut-off values of BMI for estimation of increased risk of metabolic disorders: $23.1-24.4 \mathrm{~kg} / \mathrm{m}^{2}$ for East Asians, $26.6-26.8 \mathrm{~kg} / \mathrm{m}^{2}$ for South Asians, and $26.3-28.2 \mathrm{~kg} / \mathrm{m}^{2}$ for Canadians of the European origin.

In the study in population of Taiwan, ${ }^{(20)}$ following cut-offs of anthropometrical data for obesity and excess weight were received: BMI 23.6 and $22.1 \mathrm{~kg} / \mathrm{m}^{2}$, WC 80.5 and $71.5 \mathrm{~cm}$, WHR 0.85 and 0.76 , accordingly, for men and women.

Thus, based on the abovementioned results, the aim of our study was to develop anthropometrical reference data for women of Uzbek nationality.

\section{Material and Methods}

This study was performed by a group of endocrinologists in the Tashkent, Qashqadarya, and Khorezm regions of Uzbekistan among women of Uzbek nationality aged 35 years and older. The sample was formed by the method of random numbers, and the design of sample formation was weighed cluster.

Inclusion criteria were female sex, age $\geq 35$ years, absence of components of MS, and cardiovascular events in anamnesis. Exclusion criteria were high risk of T2D development, diabetes, prediabetes, $\mathrm{BP}>130 / 85 \mathrm{mmHg}$ at the moment of measurement, receiving hypotensive medications, or having episodes of BP increase in the anamnesis.

In total, 1413 women of Uzbek nationality aged $\geq 35$ years were studied; of them, 411 had no obesity, excess body weight (according to WHO criteria for European population), carbohydrate metabolism disorders, or hypertension. The study included filling out a questionnaire based on the FinnishDiabetesRiskScore with assessment of T2D risk. ${ }^{(3,7)}$ Body weight was measured using on-floor scales (in $\mathrm{kg}$ ); growth - using auxanometer (in $\mathrm{cm}$ ), WC - using centimetric tape at the navel level on a horizontal line (in cm), HC- using centimetric tape on the most prominent points at the level of the hips (in $\mathrm{cm}$ ). BMI was calculated according to the formula: BMI $\left(\mathrm{kg} / \mathrm{m}^{2}\right)=($ weight, $\mathrm{kg}) /(\text { growth, } \mathrm{cm})^{2}{ }^{(21,10)} \mathrm{WHR}$ ratio was calculated as WC/HC. ${ }^{(21,10)}$

All patients were checked on office BP using Korotkov's method after a 5-min rest in the seated position with back support. BP was measured two times on the left and right arms at 2-minute intervals with the use of a validated semiautomated electronic device. Blood pressure was measured using Korotkov's method on two hands twice.

All women were tested for FPG and a 2-hour OGTT. Prediabetes and diabetes were diagnosed according to the international recommendations. ${ }^{(22)}$

Statistical analysis was performed using the statistical software STATISTICA 6.0. The mean (M) and standard deviation (SD) were calculated. For normally distributed data, the percentile values were calculated. The references ranges were those between the 5 th and 95 th percentile values. ${ }^{(12,14)}$

\section{Results}

\section{BMI in women of $U$ z, bek nationality}

BMI was calculated for 411 women. The average BMI value was $22.49 \pm 1.72 \mathrm{~kg} / \mathrm{m}^{2}$. Considering recommendations to use a BMI value of $23 \mathrm{~kg} / \mathrm{m}^{2}$ as the cut-off in Asians, we divided the women into two subgroups, with BMI $18-23 \mathrm{~kg} / \mathrm{m}^{2}$ and BMI $23-25 \mathrm{~kg} / \mathrm{m}^{2}$, and found that the number of women in the two subgroups was nearly identical (54\% and $46 \%$, accordingly); therefore, if one decreases the BMI reference from 25 to $23 \mathrm{~kg} / \mathrm{m}^{2}$, half of the women with "normal" BMI, according to European criteria, will automatically become members of the group with excess body weight. Therefore, calculating a reference BMI for the Uzbek female population, we considered it sensible to follow the European criteria recommended by WHO/IDF. We calculated percentiles for BMI in women to reveal their reference values (Table 4). Thus, the reference values of BMI for Uzbek women vary from 19.4 to $24.8 \mathrm{~kg} / \mathrm{m}^{2}$; BMI $22.7 \mathrm{~kg} / \mathrm{m}^{2}$ corresponds to the $50^{\text {th }}$ percentile. These results correspond to the WHO criteria for European populations. ${ }^{(6)}$

\section{WC in women of $U$ zbek nationality}

Average WC was $76.06 \pm 7.98 \mathrm{~cm}$. The reference range of WC varied from 65.0 to $90.0 \mathrm{~cm}$. The conventional cut-off for normal $\mathrm{WC}(80 \mathrm{~cm})$ corresponded to the $75^{\text {th }}$ percentile of the analysis among women of Uzbek nationality without any carbohydrate metabolism disorders and with normal BMI. 
WC equal to $76 \mathrm{~cm}$ corresponds to the $50^{\text {th }}$ percentile (Table 4). Thus, the cut-off of WC for Uzbek women is $90.0 \mathrm{~cm}$, which is a mismatch to the European criteria.

\section{$H C$ in women of $U_{z}$ bek nationality}

Concerning $\mathrm{HC}$, this indicator itself is not informative when isolated from WC. However, it is important for a definition of the type of fat distribution in the presence of obesity or excess body weight. Average $\mathrm{HC}$ among the studied women was $95.73 \pm 6.93 \mathrm{~cm}$. Reference values of HC vary from 84.0 to $107.0 \mathrm{~cm}$. HC of $100 \mathrm{~cm}$ corresponds to the $75^{\text {th }}$ percentile. The $50^{\text {th }}$ percentile is represented by HC $96.0 \mathrm{~cm}$ (Table 4). The reference values differ from the European and Asian data.

\section{WHR in women of $U$ zbek nationality}

Average value of WHR was $0.80 \pm 0.07$. Reference values of WHR vary of 0.69 to 0.93 . WHR 0.8 corresponds to the $80^{\text {th }}$ percentile (Table 4 ).

\section{Table 4.}

Percentile values of BMI, WC, HC, and WHR for women of Uzbek nationality aged $\geq 35$ years.

\begin{tabular}{|l|l|l|l|l|}
\hline Percentile & $\mathrm{BMI}, \mathrm{kg} / \mathrm{m}^{2}$ & $\mathrm{WC}, \mathrm{cm}$ & $\mathrm{HC}, \mathrm{cm}$ & WHR \\
\hline Percentile 2.5 & 18.8 & 63.8 & 82.0 & 0.68 \\
\hline Percentile 5 & 19.4 & 65.0 & 84.0 & 0.69 \\
\hline Percentile 10 & 20.0 & 67.3 & 86.0 & 0.71 \\
\hline Percentile 25 & 21.2 & 70.3 & 91.0 & 0.75 \\
\hline Median 50 & 22.7 & 76.0 & 96.0 & 0.80 \\
\hline Percentile 75 & 24.0 & 80.0 & 100.0 & 0.84 \\
\hline Percentile 90 & 24.6 & 87.7 & 104.0 & 0.88 \\
\hline Percentile 95 & 24.8 & 90.0 & 107.0 & 0.93 \\
\hline Percentile 97.5 & 24.9 & 93.0 & 110.0 & 0.95 \\
\hline
\end{tabular}

\section{Discussion}

In 1996, the WHO Expert Committee published recommendations not to develop any reference values of BMI for adults ${ }^{(6)}$ and to use in practice the threshold values of BMI, as the prevalence of excess weight and obesity varies widely in different countries. The Committee explained that different populations with identical distribution of BMI have different relative risks of morbidity and mortality, and the prevalence of obesity depends on the social welfare of a population. Thus, experts believe that in the future, if enough data is gathered, reference values of BMI still may be developed. Such data should be gathered in populations without problems with nutrition, in which growth in childhood is not influenced by chronic infections, and youth in the population are basically healthy and do not smoke. In addition to the experts' recommendations, we have excluded from our study persons with abnormal weight, both excessive and insufficient (referring to non-pregnant persons with good nutritional status), persons with obvious diseases, and those who are on special diets to lose weight.

Threshold values of BMI $>25 \mathrm{~kg} / \mathrm{m}^{2}$ for excess weight and $>30 \mathrm{~kg} / \mathrm{m}^{2}$ for obesity were received from the European populations. However, the South Asian populations ${ }^{(5,19,23)}$ have increased risk of $\mathrm{T} 2 \mathrm{D}$, hypertension and dislipidemia even with BMI $<25 \mathrm{~kg} / \mathrm{m}^{2}$. A possible explanation is that there is a relatively lower muscular weight and higher fat mass among these populations compared to Europeans. For the Asian populations, two positions of consensus tried to define BMI interval. In WHO's position dated 2000, ${ }^{(4)} \mathrm{BMI}>23 \mathrm{~kg} / \mathrm{m}^{2}$ was recommended to consider as excess weight, and $>25 \mathrm{~kg} / \mathrm{m}^{2}$ as obesity. Moreover, in 2004, WHO's position specified that there are many threshold BMI values for Asians for a definition of excess weight and obesity, and it is impossible to deduce any common value in these populations. ${ }^{(11)}$

The difference in the received average data depends on the study method - getting an average data in populations, carrying out the ROC-analysis, or the multivariate analysis of risk factors; and within the multivariate analysis, methods of revealing threshold values of anthropometrical indicators also differ essentially. So for example, F. Razak has received the following average indexes depending on demographic characteristics: BMI for Europeans - $27.5 \mathrm{~kg} / \mathrm{m}^{2}$ (27.0-28.0), for South Asians - $26.1 \mathrm{~kg} / \mathrm{m}^{2}$ (25.6-26.6), for Chinese - 23.7 $\mathrm{kg} / \mathrm{m}^{2}(23.2-24.2)$, and for native Canadians $-31.2 \mathrm{~kg} / \mathrm{m}^{2}$ (30.6-31.8); WC for European women - $84.7 \mathrm{~cm}$ (82.7-86.6), for Southern Asians - $85.7 \mathrm{~cm}$ (83.9-87.5), for Chinese women - $74.8 \mathrm{~cm}$ (73.6-76), for native Canadians - $97.0 \mathrm{~cm}$ (94.499.7).It is interesting that the HOMA-IR index also increases with the increase in BMI and WC:. for Europeans - 2.29(2.052.54), for South Asians - 3.18(2.93-3.43), for Chinese 2.46(2.2-2.71) and for native Canadians - 4.62 (4.33-4.92).

F. Razak et al. ${ }^{(17)}$ showed that South Asians, Chinese, and natives of Canada have a similar distribution of factors of carbohydrate metabolism (fasting and 2-hour glucose, fasting and 2-hour insulin, HbA1c, HOMA-IR) and lipid metabolism (LDL, HDL, fasting and 2-hour triglycerides, fasting and 2-hour free fatty acids) at much lower values of BMI compared to Europeans, and the use of European norms of BMI in the given populations will lead to underestimating risk. Therefore, to minimize development of cardiometabolic risk factors in some non-European populations, health professionals should use lower goal values of BMI. The data we received in our study correspond to Razak's conclusions. A study by W. Lin et al. ${ }^{(20)}$ among Taiwanese population also has led to the conclusion that values of BMI and WC for the Taiwanese population should be lower than the values received for the Western countries. Thus, the top border of normal BMI for women is $22.1 \mathrm{~kg} / \mathrm{m}^{2}, \mathrm{WC}-71.5 \mathrm{~cm}$, and WHR -0.76 .

F. Razak et al. also showed the influence of ethnic features on the ratio of obesity and glucose metabolism disorders. ${ }^{(17,18)}$ For example, 58.8\% of South Asians with increased WC (for the European population) will have $\mathrm{BMI}<30 \mathrm{~kg} / \mathrm{m}^{2}$, which underlines the necessity, first, of an obligatory account of $\mathrm{WC}$ in an estimation of CV risk, and, second, of working out reference values of WC for the given population.

Dudeja et al. ${ }^{(24)}$ summarized data on different BMI values received for different ethnic groups. Thus, the cut-off of normal BMI in women varies from $22.1 \mathrm{~kg} / \mathrm{m}^{2}$ in Singapore Chinese and mainland Chinese, to $22.5 \mathrm{~kg} / \mathrm{m}^{2}$ in East Asians, $27.0 \mathrm{~kg} / \mathrm{m}^{2}$ in South Asians and black inhabitants of Jamaica, 
$29.7 \mathrm{~kg} / \mathrm{m}^{2}$ in Polynesians, and $30.9 \mathrm{~kg} / \mathrm{m}^{2}$ in inhabitants of the USA. For Indian women of Northern regions of India authors have received BMI value of $23.3 \mathrm{~kg} / \mathrm{m}^{2}$.

However, the study by $\mathrm{S}$. Oh ${ }^{(25)}$ did not confirm the rationale for use of lower threshold values of BMI for revealing of risks. The authors recommended using BMI $25 \mathrm{~kg} / \mathrm{m}^{2}$ as the threshold to start actions on prevention of obesity.

The age of the observed people varies in the abovementioned studies. Therefore, we consider it reasonable to deduce a reference range for each age group as it has been specified in the WHO recommendations. ${ }^{(6)}$ Usually, borders of reference values, in particular $\mathrm{WC}$, are calculated as the $5^{\text {th }}$ and $95^{\text {th }}$ percentiles; however, ideally such criteria should be based on their association with risk factors, in particular with the HOMA index.

In a study by $\mathrm{C}$. Wen et al., ${ }^{(5)}$ the authors recommend using BMI $\geq 25 \mathrm{~kg} / \mathrm{m}^{2}$ as the threshold value for obesity and $23-24.9 \mathrm{~kg} / \mathrm{m}^{2}$ for excess weight in Asians. The authors specify that following the European standards leads to underestimating the contribution of obesity to the reasons for lethal outcomes among Asians.

In many studies, data are provided together with an estimation of risk factors for diabetes, hypertension, and dyslipidemia. We plan to carry out a similar analysis on the threshold values of anthropometrical data we receive and to develop data adapted to the Uzbek population in a way that is easy to use in clinical practice the questionnaires for estimating risk of CVD development. In further studies, we will investigate whether the CV risk is higher in the population with BMI higher than the obtained reference values, but lower than the values received for Europeans.

In conclusion, for women of Uzbek nationality:

- the cut-off value of BMI is $24.8 \mathrm{~kg} / \mathrm{m}^{2}$;

- the cut-off value of $\mathrm{WC}$ is $90 \mathrm{~cm}$;

- the cut-off value of $\mathrm{HC}$ is $107 \mathrm{~cm}$;

- the cut-off value of WHR is 0.93 .

We recommend using the reference ranges we have received during epidemiological studies in order to reveal the prevalence of MS and its components at the first stage of research, according to $\mathrm{WHO}$ - at the stage of revealing of risk groups.

\section{Competing interests}

The authors declare that they have no competing interests.

\section{Acknowledgements}

The authors gratefully acknowledge the team of endocrinologists headed by prof. Zair S. Akbarov for their help in data collection.

\section{References}

1. Grundy SM, Cleeman JI, Daniels SR, Donato KA, Eckel RH, Franklin BA, et al. Diagnosis and management of the metabolic syndrome: an American Heart Association/ National Heart, Lung, and Blood Institute scientific statement:
Executive Summary. Crit Pathw Cardiol. 2005;4(4):198-203. 2. Aguiree F, Brown A, Cho NH, Dahlquist G, Dodd Sh, Dunning T, et al. IDF Diabetes Atlas: sixth edition. Basel: International Diabetes Federation; 2013.

3. Lindstrom J, Tuomilehto J. The diabetes risk score: a practical tool to predict type 2 diabetes risk. Diabetes Care. 2003;26(3):725-31.

4. Obesity: preventing and managing the global epidemic. Report of a WHO Consultation (WHO Technical Report Series 894). Geneva: World Health Organization; 2000.

5. Wen CP, David Cheng TY, Tsai SP, Chan HT, Hsu HL, Hsu CC, Eriksen MP. Are Asians at greater mortality risks for being overweight than Caucasians? Redefining obesity for Asians. Public Health Nutr. 2009;12(4):497-506. doi: 10.1017/S1368980008002802.

6. de Onis M, Habicht JP. Anthropometric reference data for international use: recommendations from a World Health Organization Expert Committee. Am J Clin Nutr. 1996;64(4):650-8.

7. Saaristo T, Peltonen M, Lindstrom J, Saarikoski L, Sundvall J, Eriksson JG, et al. Cross-sectional evaluation of the Finnish Diabetes Risk Score: a tool to identify undetected type 2 diabetes, abnormal glucose tolerance and metabolic syndrome. Diab Vasc Dis Res. 2005;2(2):67-72.

8. IDF Consensus Worldwide Definition of the Metabolic Syndrome, 2006. Available from: https://www.idf.org/elibrary/consensus-statements/60-idfconsensus-worldwidedefinitionof-the-metabolic-syndrome

9. Stern MP, Williams K, González-Villalpando C, Hunt KJ, Haffner SM. Does the metabolic syndrome improve identification of individuals at risk of type 2 diabetes and/or cardiovascular disease? Diabetes Care 2004;27(11):2676-81.

10. V. R. Preedy (ed.), Handbook of Anthropometry: Physical Measures of Human Form in Health and Disease, DOI 10.1007/978-1-4419-1788-1_2, (C) Springer Science+Business Media, LLC 2012

11. Anuurad E, Shiwaku K, Nogi A, Kitajima K, Enkhmaa B, Shimono K, et al. The new BMI criteria for asians by the regional office for the western pacific region of WHO are suitable for screening of overweight to prevent metabolic syndrome in elder Japanese workers. J Occup Health. 2003;45(6):335-43.

12. Polyakov VC, Averyanov AP, Bolotova NB. [Body mass index and waist circumference standards: their role in the diagnosis of obesity]. Pediatria. 2009; 88(6):17-20. [Article in Russian].

13. Jafar TH, Islam M, Poulter N, Hatcher J, Schmid CH, Levey AS, Chaturvedi N. Children in South Asia have higher body mass-adjusted blood pressure levels than white children in the United States: a comparative study. Circulation. 2005;111(10):1291-7.

14. Azimova Sh, Rakhimova G. Waist circumference percentiles in a nationally representative sample of 7-18 years old Uzbek children and adolescents. Medical and Health Science Journal. 2013;14(3):123-27.

15. Haldar S, Chia SC, Henry CJ. Body Composition in Asians and Caucasians: Comparative Analyses and Influences on Cardiometabolic Outcomes. Adv Food Nutr Res. 2015;75:97154. doi: 10.1016/bs.afnr.2015.07.001.

16. He M, Li ET, Harris S, Huff MW, Yau CY, Anderson GH. Canadian global village reality: anthropometric surrogate cutoffs and metabolic abnormalities among Canadians of East Asian, South Asian, and European descent. Can Fam 
Physician. 2010;56(5):e174-82.

17. Razak F, Anand SS, Shannon H, Vuksan V, Davis B, Jacobs R, et al. Defining obesity cut points in a multiethnic population. Circulation. 2007;115(16):2111-8.

18. Razak F, Anand S, Vuksan V, Davis B, Jacobs R, Teo $\mathrm{KK}$, Yusuf S; SHARE Investigators. Ethnic differences in the relationships between obesity and glucose-metabolic abnormalities: a cross-sectional population-based study. Int J Obes (Lond). 2005;29(6):656-67.

19. Deurenberg-Yap M, Schmidt G, van Staveren WA, Deurenberg P. The paradox of low body mass index and high body fat percentage among Chinese, Malays and Indians in Singapore. Int J Obes Relat Metab Disord. 2000;24(8):1011-7. 20. Lin WY, Lee LT, Chen CY, Lo H, Hsia HH, Liu IL, et al. Optimal cut-off values for obesity: using simple anthropometric indices to predict cardiovascular risk factors in Taiwan. Int J Obes Relat Metab Disord. 2002;26(9):1232-8.
21. Hermanussen M, Meigen C. Synthetic standards for body weight. Homo. 2003;54(2):142-56.

22. Definition and diagnosis of diabetes mellitus and intermediate hyperglycemia. Report of a WHO/IDF consultation. WHO, IDF; 2006. Available from: http://apps. who.int/iris/bitstream/10665/43588/1/9241594934_eng.pdf

23. Boffetta P, McLerran D, Chen Y, Inoue M, Sinha R, He J, et al. Body mass index and diabetes in Asia: a cross-sectional pooled analysis of 900,000 individuals in the Asia cohort consortium. PLoS One. 2011;6(6):e19930. doi: 10.1371/ journal.pone.0019930.

24. Dudeja V, Misra A, Pandey RM, Devina G, Kumar G, Vikram NK. BMI does not accurately predict overweight in Asian Indians in northern India. Br J Nutr. 2001;86(1):105-12. 25. Oh SW, Shin SA, Yun YH, Yoo T, Huh BY. Cut-off point of BMI and obesity-related comorbidities and mortality in middle-aged Koreans. Obes Res. 2004;12(12):2031-40. 